\title{
ACCESIBILIDAD DE LAS PERSONAS CON DISCAPACIDAD EN ESPAÑA Y PORTUGAL: PERSPECTIVA JURÍDICA
}

\author{
Accessibility of people with disabilities in Spain and Portugal: legal perspective
}

Recibido: 19 de octubre de 2020

Aceptado: 13 de enero de 2021

\author{
Juana Tejada Ríos \\ Profesora sustituta interina de Trabajo Social \\ riosscol@uma.es \\ Universidad de Málaga
}

\section{RESUMEN}

En este artículo se presenta de forma descriptiva y comparativa cómo se ha ido avanzando, en la promoción e implantación de medidas para conseguir una mayor accesibilidad para las personas con discapacidad, desde la perspectiva jurídica y administrativa en España y Portugal. La accesibilidad es el medio principal para lograr la plena integración y participación en la sociedad, así como el presupuesto ineludible para el ejercicio de los derechos que amparan a este sector importante de la población. Se trata de un derecho reconocido en el Convenio Internacional sobre los Derechos de las Personas con Discapacidad, presidido por la Declaración Universal de los Derechos Humanos.

En relación a este derecho, y desde la perspectiva portuguesa y española, se están desarrollando simultáneamente normas que lo regulan y amparan. Por ello, en el presente trabajo se realiza un análisis descriptivo del desarrollo legislativo en ambos países y se confrontan distintos planteamiento. La accesibilidad necesita medidas que asocien inclusión, derechos humanos y equidad social para las personas con discapacidad. Por ello es fundamental que las diferentes administraciones demuestren actitudes positivas en sus prácticas, para asegurar el acceso en igualdad de condiciones con los demás, con el objeto de conseguir su plena integración en la sociedad.

\section{PALABRAS CLAVE}

accesibilidad universal, integración, derechos humanos, discriminación, regulación normativa.

\section{ABSTRACT}

This article presents in a descriptive and comparative way how progress has been made, in the promotion and implementation of measures to achieve greater accessibility for people with disabilities, from the legal and administrative perspective in Spain and Portugal. Accessibility is the main means to achieve full integration and participation in society, as well as the unavoidable budget for the exercise of the rights that protect this important sector of the population. It is a right recognized in the International Convention on the Rights of Persons with Disabilities, chaired by the Universal Declaration of Human Rights.

In relation to this right, and from the Portuguese and Spanish perspective, norms that regulate and protect it are being developed simultaneously. Therefore, in this work a descriptive analysis of the legislative development in both countries is carried out and different approaches are confronted. Accessibility needs measures that associate inclusion, human rights and social equity for people with disabilities. For this reason, it is essential that the different administrations demonstrate positive attitudes in their practices, to ensure access on equal terms with others, in order to achieve their full integration into society.

\section{KEYWORDS}

universal accessibility, integration, human rights, discrimination, normative regulation. 
Sumario: 1. Introducción. 2. Tratamiento de la Discapacidad en la Constitución: Perspectiva comparada entre España y Portugal. 3. Evolución de la regulación normativa sobre accesibilidad en España, en referencia a las personas con discapacidad. 4. Evolución de la regulación sobre accesibilidad en Portugal, en referencia a las personas con discapacidad. 5. Discusión de resultados. 6. Conclusiones. 7. Bibliografía. 8. Webs de interés.

\section{Introducción.}

La accesibilidad constituye un elemento fundamental en la calidad de vida de las personas con discapacidad, siendo un medio imprescindible para la integración y participación en la vida pública, y un presupuesto ineludible para el ejercicio de derechos fundamentales, como la libertad de circulación, de comunicación y de expresión, entre otros.

A lo largo de la historia se han producido importantes cambios en la legislación para adaptarse a una sociedad cambiante y compleja, donde la diversidad humana es una realidad incuestionable y un valor añadido.

La dignidad de la persona en su versión tradicional se construía sobre las capacidades humanas, la utilidad social y la naturaleza instrumental de los derechos, asignándose solo a aquellas personas que alcanzaban el grado socialmente estimado en el desarrollo de sus capacidades racionales, comunicativas y sensitivas. Esto implicaba que aquellas personas que presentaran deficiencias en sus capacidades no eran dignas y por tanto no eran titulares de derechos, por lo que solo podían percibir ayudas graciables por parte del Estado para cubrir sus necesidades de subsistencia, constituyéndose en una carga social. ${ }^{1}$

A partir de la teoría de los derechos humanos, la dignidad es un atributo consustancial a la persona, con independencia del patrón asignado a la "normalidad" en cada momento histórico. El respeto a la dignidad de las personas con discapacidad exige el reconocimiento de su libertad moral y el ejercicio de su autodeterminación, a través del ejercicio de decisiones autónomas para forjar su propio destino vital. Para ello los poderes públicos han de abandonar las tradicionales políticas públicas proteccionistas y asistenciales, basadas constante asistencia de un tercero. La garantía de la dignidad de las personas con discapacidad reclama no solo el reconocimiento de la titularidad formal de los derechos, sino especialmente la igualdad en el ejercicio de los mismos, con la finalidad de asegurar una vida buena a todos los ciudadanos. Los derechos son un instrumento al servicio de la libertad moral de las personas, sin los cuales no podríamos orientar nuestra existencia a la consecución de objetivos predefinidos. ${ }^{2}$

El Convenio Internacional sobre los Derechos de las Personas con Discapacidad, presidido por la Declaración Universal de los Derechos Humanos (1948), junto con los Pactos Internacionales de derechos civiles, políticos, sociales, económicos y culturales (1966) y sus dos Protocolos facultativos conforman la Carta Internacional de Derechos Humanos, tienen como finalidad construir un corpus jurídico tuitivo que garantiza los derechos y libertades fundamentales de los ciudadanos en todo el mundo. Esta labor se ha visto facilitada por otros instrumentos jurídicos sobre la misma materia: la Convención Europea de Derechos Humanos (1950), la Convención Interamericana de Derechos Humanos (1969) y la Carta Africana de Derechos Humanos (1981). Sin embargo, no fue suficiente para que los Estados Parte de los diferentes tratados internacionales respetaran los derechos fundamentales de las personas con

\footnotetext{
${ }^{1}$ Veáse ALLPORT, G. W. (1962), La naturaleza del prejuicio, Buenos Aires: Eudeba.

${ }^{2}$ Véase ASÍS, R. (2007)’Derechos humanos y discapacidad. Algunas reflexiones derivadas del análisis de la discapacidad desde la teoría de los derechos", en CAMPOY CERVERA, I. Y PALACIOS, A., Igualdad, no discriminación y discapacidad, Madrid: Dykinson.
} 
discapacidad, motivando la elaboración de la Convención sobre los Derechos de las Personas con Discapacidad, firmada en Nueva York el 13 de diciembre de $2006{ }^{3}$

La Convención no es una declaración programática sino que tiene un carácter jurídico vinculante, siendo un punto de inflexión en el tratamiento de la discapacidad. En primer lugar sitúa las políticas integradoras propias del modelo social y relega a un segundo plano las deficiencias físicas, psíquicas o sensitivas en que se materializaba la discapacidad. El Tratado considera que la discapacidad resulta "de la interacción entre las personas con deficiencias y las barreras debidas a la actitud y al entorno que evitan su participación plena y efectiva en la sociedad, en igualdad de condiciones con las demás", rompiendo con el paradigma tradicional, implementando el modelo social que considera la discapacidad como un complejo conjunto de condiciones, muchas de las cuales son creadas o agravadas por la sociedad, impidiendo a las personas con deficiencia el ejercicio de sus derechos. En consecuencia se debe adaptar el medio a la persona y no al revés como se venía tradicionalmente estableciendo. ${ }^{4}$

El tratamiento de la discapacidad desde la perspectiva de los derechos fundamentales es la gran aportación jurídico-política de la Convención sobre los Derechos de las Personas con Discapacidad, constituyéndose en un elemento fundamental para la reformulación de sus derechos y haciendo especial hincapié en la garantía de su eficacia en orden a que los Estados Parte implementen las acciones positivas oportunas que hagan posible el ejercicio autónomo de sus derechos y dejen de ser ciudadanos con un déficit de ciudadanía, estableciendo una serie de principios como "el respeto de la dignidad inherente, la autonomía individual, incluida la libertad de tomar las propias decisiones, y la independencia de las personas; la no discriminación; el respeto por la diferencia y la aceptación de las personas con discapacidad como parte de la diversidad y la condición humana; la igualdad de oportunidades; la accesibilidad; la igualdad entre el hombre y la mujer"5.

La Convención también ha establecido cuatro nuevos derechos para las personas con discapacidad: igual capacidad jurídica, vida independiente e inclusión social el uso de la lengua de signos y la accesibilidad universal. ${ }^{6}$

En relación a este último derecho, y desde la perspectiva portuguesa y española, se están desarrollando simultáneamente normas que lo regulan y amparan. Por ello, en el presente trabajo se realiza un análisis descriptivo del desarrollo legislativo en ambos países.

\section{Tratamiento de la Discapacidad en la Constitución: Perspectiva comparada entre España y Portugal.}

La promoción y la implantación de medidas para lograr el pleno ejercicio de los derechos que amparan a las personas con discapacidad es responsabilidad de ambos Estados, de acuerdo con su normativa interna desarrollada en base a los mandatos constitucionales y en aplicación de la Convención sobre los Derechos de las Personas con Discapacidad

En Europa occidental existe un reducido número de países que han incorporado alguna referencia a las personas con discapacidad en sus respectivas Constituciones. En el caso de

\footnotetext{
${ }^{3}$ NACIONES UNIDAS. Personas con Discapacidad. Departamento de Asuntos Económicos y Sociales. [En línea]: https://www.un.org/development/desa/disabilities-es/

4 PALACIOS, A. (2008) El modelo social de discapacidad: orígenes, caracterización y plasmación en la Convención Internacional sobre los Derechos de las personas con discapacidad. Madrid: Ediciones Cinca.

${ }^{5}$ Artículo 3, Convención sobre los Derechos de las Personas con Discapacidad, firmada en Nueva York el 13 de diciembre de 2006.

6 NACIONES UNIDAS. Oficina del Alto Comisionado para los Derechos Humanos. [En línea]: https://www.ohchr.org/documents/publications/advocacytool_sp.pdf
} 
España y Portugal, ambos países regulan en el articulado constitucional la protección de las personas con discapacidad.

La Constitución Española de 1978, regula el precepto correspondiente a las personas con discapacidad en el artículo 49.

La parte dogmática de la Constitución española es deudora, en gran medida, de su homónima portuguesa, apreciándose su influencia en el tenor literal del artículo.

"Los poderes públicos realizarán una política de previsión, tratamiento, rehabilitación e integración de los disminuidos físicos, sensoriales y psíquicos, a los que prestarán la atención especializada que requieran y los ampararán especialmente para el disfrute de los derechos que este Título otorga a todos los ciudadanos."

El contenido sustantivo de este precepto estaba recogido esencialmente en el artículo 42 del Anteproyecto constitucional y quedó prácticamente definido en el texto propuesto por la Ponencia del Congreso. ${ }^{7}$ No fue apenas objeto de debate en el proceso constituyente por dos motivos: "primero, la sensibilidad general e indiscutible, incluso aunque fuese en términos puramente políticos, hacia el reconocimiento constitucional de este sector específico de la población española; en segundo lugar, el significado del artículo 49 como estricto derecho social, es decir como precepto "voluntarista" que expresa el sentimiento de solidaridad a seguir por los poderes públicos en su función asistencial, pero que no configura en absoluto un derecho subjetivo"8

El principal precedente del mencionado artículo, se encuentra en el artículo 71 de la Constitución de la República Portuguesa de 1976, ${ }^{9}$ que adopta de forma inédita el enfoque holístico o integral del fenómeno de la discapacidad expresado en los siguientes términos:

"1. Los ciudadanos portadores de deficiencia fisica o mental gozan plenamente de los derechos y están sujetos a los deberes establecidos en la Constitución, con excepción del ejercicio o del cumplimiento de aquéllos para los cuales se hallen incapacitados.

2. El Estado se obliga a realizar una política nacional de prevención y de tratamiento, rehabilitación e integración de los ciudadanos portadores de deficiencia, y de apoyo a sus familias; a desarrollar una pedagogía que sensibilice a la sociedad en cuanto a los deberes de respeto y solidaridad para con ellos y a asumir la carga de la realización efectiva de sus derechos, sin perjuicio de los derechos y deberes de los padres o tutores.

\section{El Estado apoya las organizaciones de ciudadanos portadores de deficiencia."}

Del tenor literal de este artículo se desprende que la Constitución portuguesa contiene previsiones normativas específicas para la protección integral y efectiva de los derechos de las personas con discapacidad, y la obligación del Estado de realizar políticas para hacerlas efectivas complementándose con lo establecido en el artículo 12 que proclama el principio de universalidad de derechos y las obligaciones fundamentales y de igualdad consagradas en el

\footnotetext{
${ }^{7}$ Sobre el proceso de redacción del artículo 49 por las Cortes Constituyentes de 1977, véase TORRES DEL MORAL, A. (2010) "La incorporación de los derechos de los discapacitados por el constitucionalismo de la segunda posguerra", en Terol Becerra, M. J. (director), III Foro andaluz de los derechos sociales. Diversidad y ciudadanía, Valencia :Tirant lo Blanch.

${ }^{8}$ Veáse GARCÍA MARTÍNEZ, A. y SIEIRA, S., «Sinopsis del Artículo 49», Congreso de los Diputados, Madrid, 2003. [En línea]:

https://app.congreso.es/consti/constitucion/indice/sinopsis/sinopsis.jsp?art=49\&tipo=2\#: :text=49\%20son\%2C\%2 0seg\%C3\%BAn\%20el\%20tenor,habituales\%20de\%20la\%20vida\%20social.

${ }^{9}$ CONSTITUCIÓN DE PORTUGAL, 1976. [En línea]:

https://constituteproject.org/constitution/Portugal_2005.pdf?lang=es
} 
artículo 13, en consonancia con el propósito de la Convención sobre los Derechos de las Personas con Discapacidad. ${ }^{10}$

Respecto su homónima española dichos artículos se corresponden con el 9.2 que " refleja la dimensión social del Estado de Derecho e impone determinados cometidos a sus poderes, pero no reconoce derecho subjetivo alguno que sea susceptible de protección de amparo", ${ }^{11}$ y el artículo 14 que establece la igualdad ante la ley y la prohibición de la discriminación.

Llama poderosamente la atención que los constituyentes españoles utilizaran la peyorativa denominación de "disminuidos", que implica un desvalor hacia las personas con discapacidad, cuando la Constitución portuguesa, aprobada dos años antes, ya empleaba la respetuosa expresión de "ciudadanos portadores de deficiencia".

En consecuencia se hace necesaria la modificación nominal vigente en la Carta Magna española para referirse a este nutrido grupo social, que ponga el énfasis en la dignidad humana, en la condición de sujetos titulares de derechos. Al respecto el 10 de diciembre de 2018 el Consejo de Ministros aprobó a iniciativa de la vicepresidenta del Gobierno, ministra de la Presidencia, Relaciones con las Cortes e Igualdad, Carmen Calvo, el Anteproyecto de reforma del artículo 49 de la Constitución, relativo a los derechos de las personas con discapacidad. ${ }^{12}$ Con esta reforma, el artículo 49 de la Constitución Española se actualiza para adaptarlo a la Convención de 2006 y se modifica íntegramente tanto desde el punto de vista del lenguaje como de su estructura y contenido. Esta nueva propuesta supone un paso más hacia el pleno reconocimiento de los derechos de las personas con discapacidad, y la eliminación de la discriminación que han venido padeciendo desde siempre, en todos los ámbitos de la vida diaria, así como en el lenguaje peyorativo usado, en referencia a sus circunstancias personales.

En conclusión y respecto a la comparativa constitucional, ambos países dedican un artículo a las personas con discapacidad, aunque la perspectiva portuguesa es mucho más avanzada en su redacción, ya que no incluyen connotaciones peyorativas al referirse a este colectivo, está basada en el modelo social frente al modelo médico rehabilitador de su homónima española y por último reconoce los derechos de estas personas y obliga a los poderes públicos directamente, no ocurriendo lo mismo en la Constitución española.

Afortunadamente estas diferencias pronto estarán resueltas con la nueva redacción que se pretende dar en el texto constitucional español, para adaptarlo a las disposiciones de la Convención sobre las Personas con Discapacidad a través del anteproyecto de ley antes mencionado, lo que no ha sido necesario en el caso de Portugal.

\footnotetext{
${ }^{10}$ NACIONES UNIDAS. Personas con Discapacidad. Departamento de Asuntos Económicos y Sociales. [En línea]: https://www.un.org/development/desa/disabilities-es/.

${ }^{11}$ Sentencia del Tribunal Constitucional 120/1990, de 27 de junio, FJ. 4. ${ }^{\circ}$.España.

${ }^{12}$ Nueva redacción del artículo 49 de la Constitución Española: "Las personas con discapacidad son titulares de los derechos y deberes previstos en este Título en condiciones de libertad e igualdad real y efectiva, sin que pueda producirse discriminación.

Los poderes públicos realizarán las políticas necesarias para garantizar la plena autonomía personal e inclusión social de las personas con discapacidad. Estas políticas respetarán su libertad de elección y preferencias, y serán adoptadas con la participación de las organizaciones representativas de personas con discapacidad. Se atenderán particularmente las necesidades específicas de las mujeres y niñas con discapacidad.

Se regulará la protección reforzada de las personas con discapacidad para el pleno ejercicio de sus derechos y deberes.

Las personas con discapacidad gozan de la protección prevista en los acuerdos internacionales que velan por sus derechos".
} 


\section{Evolución de la regulación normativa sobre accesibilidad en España, en referencia a las personas con discapacidad.}

En los últimos años, se ha producido un cambio cualitativo, de suma importancia, en el enfoque hacia la discapacidad, que ha consistido en pasar a considerar la discapacidad desde la óptica de los derechos.

Los orígenes de la regulación normativa sobre la accesibilidad en España, tienen su punto de partida en la ya citada Constitución Española de 1978, en la que por primera vez se dedica un artículo, el 49, a las personas con discapacidad. Esta disposición de cabecera fue desarrollada en 1982 por medio de una ley específica, la Ley 13/1982, de 7 de abril, de Integración Social de los Minusválidos (LISMI), contiene aspectos de accesibilidad, en concreto los artículos 54 y siguientes, referidos a la movilidad y barreras arquitectónicas. Las notas características de esta legislación son la accesibilidad como eliminación de barreras, y como parte de la asistencia social. ${ }^{13}$

El desarrollo de la LISMI, fue escaso en materia de eliminación de barreras por parte del Estado. Respetando el marco básico estatal, la competencia en materia de accesibilidad ha venido siendo asumida de manera exclusiva por las Comunidades Autónomas ${ }^{14}$, siendo la estatal una competencia de mera armonización o establecimiento de normativa básica, justificada por la necesidad de exigir una sustancial uniformidad en las condiciones de vida del colectivo de personas discapacitadas ${ }^{15}$ y por el amparo de otros títulos competenciales que inciden de manera indirecta en cuestiones relativas a la accesibilidad. ${ }^{16}$

En relación a la competencia armonizadora estatal, se pronuncia el Tribunal Constitucional ${ }^{17}$ exponiendo que aunque la competencia en materia de urbanismo es "exclusiva" de las Comunidades Autónomas, debe garantizarse la coexistencia de esta competencia con las competencias que el Estado tiene para fijar las condiciones básicas de igualdad de todos los españoles en el ejercicio de los derechos y cumplimiento de deberes constitucionales.

En 2003, con ocasión del Año Europeo de las Personas con Discapacidad, se produce un hecho de gran trascendencia en el ordenamiento jurídico de la accesibilidad en España, con la promulgación de la Ley 51/2003, de 2 de diciembre, de igualdad de oportunidades, no discriminación y accesibilidad universal de las personas con discapacidad (LIONDAU). La aprobación de esta norma legal supone un cambio de tendencia en distintos aspectos e inicia un proceso normativo en el que aún estamos inmersos en nuestro país.

Posteriormente en el Real Decreto Legislativo 1/2013, de 29 de noviembre, por el que se aprueba el Texto Refundido de la Ley General de derechos de las personas con discapacidad y de su inclusión social, se reconoce a las personas con discapacidad como titulares de una serie de derechos y a los poderes públicos como los garantes del ejercicio real y efectivo de esos derechos, de acuerdo con lo previsto en la Convención Internacional de los derechos de las personas con discapacidad. Y establece el régimen de infracciones y sanciones que garantizan las condiciones básicas en materia de igualdad de oportunidades, no discriminación y accesibilidad universal de las personas con discapacidad. Esta ley refunde, aclara y armoniza en

\footnotetext{
13 Véase CARMONA CUENCA, E. (1992) "Las normas constitucionales de contenido social: delimitación y problemática de su eficacia jurídica”, Revista de Estudios Políticos, n. ${ }^{\circ}$ 76, págs. 19-34.

${ }^{14}$ Art.148.1.3 de la Constitución Española de 1978.

${ }^{15}$ Art. $149.1 .1^{a}$ de la Constitución Española de 1978.

${ }^{16}$ Art. 149.1.8 a de la Constitución Española de 1978.

${ }^{17}$ Sentencia del Tribunal Constitucional 61/97, de 20 de marzo.
} 
un único texto, las principales leyes en materia de discapacidad: la Ley 13/1982, de 7 de abril, de integración social de las personas con discapacidad (LISMI), la Ley 51/2003, de 2 de diciembre, de igualdad de oportunidades, no discriminación y accesibilidad universal de las personas con discapacidad (LIONDAU), y la Ley 49/2007, de 26 de diciembre, de infracciones y sanciones en materia de igualdad de oportunidades, no discriminación y accesibilidad universal de las personas con discapacidad. Esta tarea de refundición ha tenido como referente principal la mencionada Convención Internacional.

En los últimos años, se ha producido importantes avances en la normativa española, en virtud del principio de transversalidad de las políticas de discapacidad ${ }^{18}$, y se han regulado cuestiones de accesibilidad en diferentes ámbitos, como:

En materia de edificación y urbanismo, la Ley 15/1995, de 30 de mayo, sobre límites del dominio sobre inmuebles para eliminar barreras arquitectónicas a las personas con discapacidad, de acuerdo con la Ley 49/1960, de 21 de julio, de Propiedad Horizontal, regula la obligación de las comunidades de propietarios a la realización de obras de adecuación de fincas urbanas ocupadas por personas con discapacidad o personas mayores de setenta años, para conseguir el acceso desde la vía pública a la finca y al uso de los elementos comunes o las instalaciones o dispositivos que favorezcan la comunicación exterior. La Ley 38/1999, de 5 de noviembre, de Ordenación de la Edificación fija los Requisitos Básicos de los edificios y actualiza y completa la configuración legal de los agentes que intervienen en el proceso de la edificación, fija sus obligaciones y establece las responsabilidades y las garantías de protección a los usuarios. En el Real Decreto 505/2007, de 20 de abril, se aprueban las condiciones básicas de accesibilidad y no discriminación de las personas con discapacidad para el acceso y la utilización de los espacios públicos urbanizados y edificaciones. En desarrollo de este Real Decreto, se han aprobado a su vez dos normas de notable importancia: el Real Decreto 173/2010, de 19 de febrero, por el que se modifica el Código Técnico de la Edificación, aprobado por el Real Decreto 314/2006, de 17 de marzo, en materia de accesibilidad y no discriminación de las personas con discapacidad, es el marco normativo que establece las exigencias básicas que deben cumplir los edificios en relación con los requisitos básicos de seguridad y habitabilidad establecidos en la Ley y el Real Decreto 7/2015, de 30 de octubre, por el que se aprueba el texto refundido de la Ley de Suelo y Rehabilitación Urbana, recoge la necesidad de que la evaluación de los edificios evalúe las condiciones básicas de accesibilidad universal y no discriminación de las personas con discapacidad para el acceso y utilización del edificio, de acuerdo con la normativa vigente, estableciendo si el edificio es susceptible o no de realizar ajustes razonables para satisfacerlas. ${ }^{19}$

Las relaciones con las Administraciones Públicas, se regulan en el Real Decreto 366/2007, de 16 de marzo, por el que se establecen las condiciones de accesibilidad y no discriminación de las personas con discapacidad en sus relaciones con la Administración General del Estado y la Ley 37/2007, de 16 de noviembre, sobre reutilización de la información del sector público, establece que los medios electrónicos de puesta a disposición de los documentos disponibles para la reutilización serán accesibles a las personas con discapacidad, de acuerdo con las normas técnicas existentes en la materia.

En relación con el transporte, la Ley 9/2013, de 4 de julio, por la que se modifica la Ley 16/1987, de 30 de julio, de Ordenación de los Transportes Terrestres y la Ley 21/2003, de 7 de

\footnotetext{
${ }^{18}$ ALONSO LÓPEZ, F., "Los ejes determinantes de las políticas de igualdad de oportunidades. La accesibilidad universal y el diseño para todos", en LORENZO, R. de y LÓPEZ BUENO, L. C. (2007) Tratado sobre discapacidad, Madrid: Aranzadi.

19 UNIVERSIDAD DE SALAMACA. Servicio de Información sobre Discapacidad. [En línea]: https://sid.usal.es/secciones/discapacidad.aspx
} 
julio, de Seguridad Aérea, regula como infracción el incumplimiento de las normas en materia de accesibilidad, posteriormente el Real Decreto-ley 3/2018, de 20 de abril, ha modificado la Ley 16/1987, de 30 de julio, de Ordenación de los Transportes Terrestres, en materia de arrendamiento de vehículos con conductor. El Real Decreto Legislativo 6/2015, de 30 de octubre, por el que se aprueba el texto refundido de la Ley sobre Tráfico, Circulación de Vehículos a Motor y Seguridad Vial, en relación con las personas con discapacidad, regula como garantía que debe prestar el Ministerio de Interior la igualdad de oportunidades, no discriminación y accesibilidad universal de las personas con discapacidad, especialmente en su calidad de conductores, en todos los ámbitos regulados en esta ley. Y la Ley 38/2015, de 29 de septiembre, del sector ferroviario, se refiere específicamente a las personas con discapacidad o con movilidad reducida, en relación a la protección de sus intereses, a las cuales les garantiza sus derechos al acceso a los servicios de transporte ferroviario de viajeros en adecuadas condiciones de calidad y seguridad y a la elección de la empresa que los preste, así como la prestación de una asistencia integral a las víctimas en caso de accidente ferroviario y la Ley 37/2015, de 29 de septiembre, de carreteras, establece que las áreas de servicio, las áreas de descanso y los aparcamientos seguros, situados en las carreteras de nuestro país, deberán reunir necesariamente condiciones de accesibilidad universal para personas con discapacidad, con arreglo a lo establecido en la normativa específica aplicable.

En cuanto a las Nuevas Tecnologías, Sociedad de la Información y Medios de Comunicación, la Ley 34/2002, de 11 de julio, de servicios de la sociedad de la información y de comercio electrónico es la primera ley en España que fija la obligación de que las páginas web de las Administraciones Públicas sean accesibles. Además, fija una fecha límite para lograr la accesibilidad de las páginas web. Desgraciadamente, la ley no establece el nivel de accesibilidad que se debe lograr. Esta ley ha sido ampliada por el Real Decreto 1494/2007, de 12 de noviembre por el que se aprueba el reglamento sobre las condiciones básicas para el acceso de las personas con discapacidad a las tecnologías, productos y servicios relacionados con la sociedad de la información y medios de comunicación social. Además ha sido corregida por la Ley 56/2007, de 28 de diciembre, que modifica la disposición adicional quinta, en relación con la accesibilidad en las páginas de Internet y sus contenidos de los Centros públicos educativos, de formación y universitarios, así como, de los Centros privados que obtengan financiación pública. La Ley 29/2005, de 29 de diciembre, de Publicidad y Comunicación Institucional, recoge la exigencia de accesibilidad de la información de las campañas especificadas en esta ley, para garantizar su acceso por las personas con discapacidad. La Ley 7/2010, de 31 de marzo, General de la Comunicación Audiovisual, ha establecido de forma expresa en el artículo 8 los derechos de las personas con discapacidad visual o auditiva, de acuerdo con las posibilidades tecnológicas y la Ley 9/2014, de 9 de mayo, General de Telecomunicaciones, establece que mediante Real Decreto se podrán establecer las condiciones básicas para el acceso de las personas con discapacidad a las tecnologías, productos y servicios relacionados con las comunicaciones electrónicas.

Por último, en relación al ejercicio del derecho a voto el Real Decreto 1612/2007, de 7 de diciembre, por el que se regula un procedimiento de voto accesible que facilita a las personas con discapacidad visual el ejercicio del derecho de sufragio.

En referencia a la regulación de la accesibilidad en el ámbito autonómico, las dos primeras Comunidades en aprobar sus leyes de discapacidad han sido Andalucía, y Castilla-La Mancha. Ambos textos, que sirvieron como base para el resto de iniciativas, incluyen referencias a la accesibilidad universal y abandonan el tradicional enfoque asistencial de esta materia para pasar a otro de tipo inclusivo, centrado en potenciar las capacidades y manteniendo la no discriminación. 
En la Comunidad autónoma de Andalucía, su Estatuto de Autonomía, en el artículo 10.3.16. establece como objetivo básico de la Comunidad Autónoma la integración social, económica y laboral de las personas con discapacidad, y para lograr su consecución, el artículo 37.1.5. recoge, entre los principios rectores de las políticas públicas de los poderes de nuestra Comunidad Autónoma, la autonomía y la integración social y profesional de las personas con discapacidad, de acuerdo con los principios de no discriminación, accesibilidad universal e igualdad de oportunidades, incluyendo la utilización de lenguajes que les permitan la comunicación y la plena eliminación de las barreras. En base a estos preceptos, la Ley 5/1998, de 23 de noviembre, relativa al uso en Andalucía de perros guía por personas con disfunciones visuales, tiene por objeto garantizar el ejercicio del derecho al libre acceso, deambulación y permanencia en lugares públicos o de uso público de las personas afectadas por disfunciones visuales que vayan acompañadas de perros guía. En desarrollo de esta Ley se dicta el Decreto 32/2005, de 8 de febrero, por el que se regula el distintivo de perro guía y el procedimiento para su concesión y se crea el Registro de perros guía de la Comunidad Autónoma de Andalucía. Asimismo, mediante el Real Decreto 173/2010, de 19 de febrero, se modifica el Código Técnico de la Edificación y mediante la Orden VIV/561/2010, de 1 de febrero, se desarrolla el documento técnico de condiciones básicas de accesibilidad y no discriminación para el acceso y utilización de los espacios públicos urbanizados, se estima necesario incluir, asimismo, en los modelos de fichas justificativas las nuevas prescripciones y parámetros estatales. En base a estas normas se dicta la Orden de 19 de septiembre de 2016, que regula las tarjetas de aparcamiento de vehículos para personas con movilidad reducida en Andalucía y la Ley 11/2011, de 5 de diciembre, regula el uso de la lengua de signos española y los medios de apoyo a la comunicación oral de las personas sordas, con discapacidad auditiva y con sordoceguera en Andalucía.

En la Aragón, el artículo 6.2.a. del Estatuto de Autonomía, establece que corresponde a los poderes públicos aragoneses promover las condiciones adecuadas para que la libertad y la igualdad del individuo y de los grupos en que se integra sean reales y efectivas; remover los obstáculos que impidan o dificulten su plenitud, y facilitar la participación de todos los aragoneses en la vida política, económica, cultural y social. Además, en virtud de lo dispuesto en el artículo $35.17^{\circ}$ y $26^{\circ}$ de dicho Estatuto, la Comunidad Autónoma de Aragón tiene asumidas competencias exclusivas en materia de ordenación del territorio, urbanismo, vivienda y en materia de asistencia, bienestar social y desarrollo comunitario. De acuerdo con dicho título competencial se promulgó el Decreto 89/1991, de 16 de abril, de la Diputación General de Aragón, para la supresión de barreras arquitectónicas, con el fin de establecer unas normas técnicas que condujesen a la supresión de las barreras arquitectónicas que dificultaban o impedían el acceso o la utilización de determinados bienes o servicios. Posteriormente se promulgó la Ley 3/1997, de 7 de abril, de Promoción de la Accesibilidad y Supresión de Barreras Arquitectónicas, Urbanísticas, de Transportes y de la Comunicación. Dicha Ley recoge un conjunto de disposiciones tendentes a eliminar los obstáculos que impiden obtener una efectiva integración de las personas en situación de limitación, comprometiendo en ello a las Administraciones Públicas y en cumplimiento de lo dispuesto en el Decreto108/2000, de 29 de mayo, se aprueba la Orden de 15 de junio de 2000, del Departamento de Sanidad, Consumo y Bienestar Social, por la que se modifica el modelo de tarjeta de estacionamiento para personas con discapacidad.

La Comunidad de Asturias, de conformidad con lo previsto en el Texto Refundido de la Ley General de derechos de las personas con discapacidad y de su inclusión social, aprobado por Real Decreto Legislativo 1/2013, de 29 de noviembre; y la obligación establecida en la Ley 19/2001, de 19 de diciembre, de reforma del texto articulado de la Ley sobre Tráfico, Circulación de Vehículos a Motor y Seguridad Vial, dicta el Decreto 58/2017, de 2 de agosto, por el que se regula el procedimiento para la obtención de la tarjeta de estacionamiento de vehículos que transportan a personas con movilidad reducida en el Principado de Asturias. 
Las Islas Baleares han sido punteras en la promoción de la accesibilidad y la supresión de barreras arquitectónicas. Actualmente, la Ley 8/2017, de 3 de agosto, de Accesibilidad Universal de las Illes Balears, se redacta con la voluntad de orientar el concepto de accesibilidad hacia un sentido universal, para evitar recorridos, accesos o espacios alternativos para personas con discapacidad; tiene en cuenta el hecho de que la discapacidad es, en muchos casos, una cuestión de grado que afecta, al menos temporalmente o circunstancialmente, a cualquier persona, y acepta la definición de accesibilidad como el conjunto de condiciones de comprensibilidad y usabilidad que deben cumplir el entorno, los espacios, los edificios, los servicios, los medios de transporte, los procesos, los productos, los instrumentos, los aparatos, las herramientas, los dispositivos, los mecanismos y los elementos análogos para que todas las personas puedan utilizarlos y puedan disfrutar de ellos con seguridad y comodidad y de la manera más autónoma y natural posible.

La Comunidad Autónoma de Canarias ha asumido de forma exclusiva, conforme establece en su artículo 29.11 y 12 el Estatuto de Autonomía, la potestad legislativa, reglamentaria y la función ejecutiva en materia de ordenación del territorio, urbanismo y vivienda, así como las obras públicas de interés de la Comunidad Autónoma. Actualmente el Decreto 148/2001, de 9 de julio, que introduce la creación de reservas de estacionamiento y modifica el carácter de la tarjeta, que será personal e intransferible y constituirá el documento acreditativo para el disfrute de derechos especiales en el estacionamiento.

En Cantabria, la Asamblea Regional de Cantabria aprobó la Ley de Acción Social de la Comunidad Autónoma de Cantabria, de 15 de mayo de 1992, la cual se inspira en principios de responsabilidad pública; universalidad e igualdad, prevención, descentralización, participación, integración y normalización; planificación y coordinación, y solidaridad, en todas las actuaciones encaminadas al bienestar social de los habitantes de Cantabria, por virtud de la competencia exclusiva en esta materia, conferida por el Estatuto de Autonomía de la Diputación Regional de Cantabria. Para alcanzar esta normalización la Ley 3/1996 de 24 de septiembre, sobre Accesibilidad y Eliminación de Barreras Arquitectónicas, Urbanísticas y de Comunicación, pretende abarcar, todos los problemas que presenta el desarrollo de las actividades de los ciudadanos, tanto en el ámbito urbano como en el rural. Posteriormente se dicta el Decreto 106/2001, de 20 de noviembre, por el que se regula la tarjeta de estacionamiento para personas con discapacidad, que tiene por objeto regular la utilización y el procedimiento para el otorgamiento de la tarjeta de estacionamiento de vehículos para personas con discapacidad.

En Castilla- León , como consecuencia de la aprobación de la Ley 2/2013, de 15 de mayo, de Igualdad de Oportunidades para las Personas con Discapacidad se aprueba el Plan Estratégico de Igualdad de Oportunidades para las personas con discapacidad que a su vez incluirá un Plan autonómico de Accesibilidad, materializándose en el acuerdo 7/2017, de 9 de febrero, en cuya elaboración han intervenido el Comité de Representantes de personas con discapacidad - CERMI y las diferentes Consejerías de la Junta de Castilla y León. ${ }^{20}$ A raíz de la promulgación de esta Ley, se ha producido un amplio desarrollo reglamentario, destacando el Real Decreto 505/2007, de 20 de abril, por el que se aprueban las condiciones básicas de accesibilidad y no discriminación de las personas con discapacidad para el acceso y utilización de los espacios públicos urbanizados y edificaciones; el Real Decreto 173/2010, de 19 de febrero, por el que se modifica el Código técnico de la edificación; el Real Decreto 1494/2007, de 12 de noviembre, por el que se aprueba el Reglamento sobre las condiciones básicas para el acceso de las personas con discapacidad a las tecnologías, productos y servicios relacionados con la sociedad de la información y medios de comunicación social y el Real Decreto 1544/2007, de 23 de noviembre, por el que se regulan

${ }^{20}$ CERMI: Comité Español de Representantes de Personas con Discapacidad [En línea]: http://www.cermi.es/cermi/ 
las condiciones básicas de accesibilidad y no discriminación para el acceso y utilización de los modos de transporte para personas con discapacidad.Finalmente, en julio de 2018 se presenta un Proyecto de Decreto, por el que se aprueba el Reglamento de Accesibilidad y supresión de Barreras en Castilla y León, el cual se organiza en dos partes claramente diferenciadas. La primera parte recoge las disposiciones de carácter general, así como las disposiciones relativas a la dotación de elementos, espacios e instalaciones accesibles que deben existir en los distintos ámbitos regulados (edificación, urbanismo, transporte y comunicación sensorial). La segunda parte recoge una serie de normas técnicas donde se regulan las características y condiciones técnicas que deben cumplir los distintos elementos, espacios o instalaciones exigidos en la parte primera.

En Castilla La Mancha, a partir de la promulgación, en 1994, de la Ley de Accesibilidad y Eliminación de Barreras en se produjo una revitalización de las actuaciones emprendidas en el campo de la accesibilidad. Más tarde el Decreto 25/96 de 27 de febrero, regula la organización y funcionamiento del Consejo Regional de Accesibilidad y el Decreto 158/97 de 2 de diciembre, del Código de accesibilidad de Castilla la Mancha, que ha desarrollado los requerimientos de la accesibilidad en cada ámbito: edificación, urbanismo, transporte y comunicación, detallando las disposiciones aplicables a los centros de trabajo, a la reserva de viviendas para personas con movilidad reducida, cuestiones relativas al uso de perros- guía, etc. Posteriormente se han publicado diferentes Órdenes que regulan diferentes aspectos relacionados con la accesibilidad. Entre ellas la Orden de 13 de junio de 2000, de la Consejería de Bienestar Social, de aplicación de la Tarjeta de Accesibilidad en Castilla La Mancha, por la que se modifica el formato de la Tarjeta de Accesibilidad y se establece el procedimiento para su concesión y renovación; la Orden de 30 de enero de 2007, de la Consejería de Bienestar Social, por la que se regula la Acreditación de Establecimientos, Instalaciones y Vehículos de Transportes Público Accesibles y la Orden de 28 de mayo de 2008, de la Consejería de Bienestar Social, por la que se establecen los parámetros exigibles a los ascensores para que reúnan la condición de accesibles en el ámbito de la Comunidad Autónoma de Castilla-La Mancha.

La importancia de la promoción de la accesibilidad como instrumento para hacer efectivo el principio de igualdad de los ciudadanos tuvo una primera aplicación en Cataluña en el Decreto 100/1984, de 10 de abril, sobre supresión de barreras arquitectónicas. Posteriormente se han ido creando diferentes normativas relacionadas con la accesibilidad en diferentes ámbitos como el Decreto 97/2002, de 5 de marzo, sobre la tarjeta de aparcamiento para personas con disminución y otras medidas dirigidas a facilitar el desplazamiento de las personas con movilidad reducida; la Ley 19/2009, de 26 de noviembre, del acceso al entorno de las personas acompañadas de perros de asistencia y la Ley 17/2010, de 3 de junio, tiene como objeto regular lengua de signos catalana como sistema lingüístico propio de las personas sordas y sordociegas signantes de Cataluña. Asimismo, mediante la Orden VIV/561/2010, de 1 de febrero, por la que se desarrolla el documento técnico de condiciones básicas de accesibilidad y no discriminación para el acceso y utilización de los espacios públicos urbanizados.

Actualmente, como consecuencia de los cambios normativos que se han producido, tanto a nivel nacional como internacional, se renueva la legislación catalana y se adecuan los mandatos legales en materia de accesibilidad en la Ley 13/2014, de 30 de octubre, de accesibilidad de la Comunidad Autónoma de Cataluña, que tiene como principal objetivo "establecer las condiciones de accesibilidad necesarias para que los espacios de uso público, los edificios, los medios de transporte, los productos, los servicios y los procesos de comunicación garanticen la autonomía, la igualdad de oportunidades y la no discriminación de las personas con discapacidad o con otras dificultades de interacción con el entorno". ${ }^{21}$

\footnotetext{
${ }^{21}$ Artículo 1, Ley 13/2014, de 30 de octubre, de accesibilidad de la Comunidad Autónoma de Cataluña.
} 
La Comunidad valenciana, asumió, en virtud de su Estatuto de Autonomía, aprobado por Ley Orgánica 5/1982, de 1 de julio, la competencia exclusiva, entre otras, en materia de asistencia social, ordenación del territorio y del litoral, urbanismo y vivienda. Con Ley 1/1998, de 5 de mayo, de la Generalitat Valenciana, de Accesibilidad y Supresión de Barreras Arquitectónicas, Urbanísticas y de la Comunicación, se pretende conseguir un entorno libre de barreras de todo tipo, evidenciando así la voluntad de integración social y la garantía del principio de igualdad. En base a estos preceptos se aprueban diferentes normas, entre ellas el Decreto 167/2006, de 3 de noviembre, del Consell, desarrolla la Ley 12/2003, de 10 de abril, de la Generalitat, sobre Perros de Asistencia para Personas con Discapacidades y el Decreto 65/2019, de 26 de abril, del Consell, regula la accesibilidad en la edificación y en los espacios públicos.

En Extremadura, en cumplimiento de lo establecido en su Estatuto de Autonomía, en la redacción dada por la Ley Orgánica 1/2011, de 28 de enero, recoge en el artículo 7.15 entre los principios rectores de los poderes públicos extremeños, promover la autonomía, la igualdad de oportunidades y la integración social y laboral de las personas con discapacidad, con especial atención a su aportación activa al conjunto de la sociedad, a la enseñanza y uso de la lengua de signos española y a la eliminación de las barreras físicas, se aprobó la Ley 11/2014, de 9 de diciembre, de accesibilidad universal de Extremadura, tiene por objeto garantizar la accesibilidad a los entornos y la utilización de los bienes y servicios de la sociedad por todas las personas en el ámbito de la Comunidad Autónoma de Extremadura. En base a lo establecido en esta norma se aprueba el Decreto 131/2018, de 1 de agosto, por el que se aprueba el Reglamento que regula las normas de accesibilidad universal en la edificación, espacios públicos urbanizados, espacios públicos naturales y el transporte en la Comunidad Autónoma de Extremadura.

La Comunidad Autónoma de Galicia, en virtud de la competencia exclusiva que en materia de Asistencia Social le atribuye el artículo 27.23 del Estatuto de Autonomía, se aprueba la Ley 4/1993, de 14 de abril, de Servicios Sociales de Galicia. Posteriormente se dicta la Ley 10/2003, de 26 de diciembre, de acceso al entorno de las personas con discapacidad acompañadas de perros de asistencia, que tiene por objeto reconocer y garantizar, en la Comunidad Autónoma de Galicia, a toda persona que como consecuencia de su discapacidad haya de ser acompañada de un perro de asistencia su derecho a acceder, deambular y permanecer con él en cualquier lugar, establecimiento o transporte de uso público, con independencia de su titularidad pública o privada.

La regulación más actual en esta materia, es el Decreto 74/2013, de 18 de abril, por el que se modifica el Decreto 35/2000, de 28 de enero, por el que se aprueba el Reglamento de desarrollo y ejecución de la Ley de accesibilidad y supresión de barreras, que contiene la normativa de aplicación a todas las actuaciones llevadas a cabo por entidades públicas o privadas, así como por las personas individuales, en materia de replanteo, gestión o ejecución urbanística; nueva construcción, rehabilitación o reforma de edificaciones; transporte y comunicación.

En la Comunidad de Madrid, desde la entrada en vigor de la Ley 8/1993, de 22 de junio, la accesibilidad se ha mostrado como un concepto en continua evolución y con transformaciones sustanciales del enfoque que debe aplicarse para su atención concreta.

Como consecuencia de la previsiones de la anterior ley se promulgó la Ley 23/1998, de 21 de diciembre, sobre acceso de las personas ciegas o con deficiencia visual usuarias de perro guía al entorno. Posteriormente, se crea la Ley 2/2015, de 10 de marzo, de Acceso al Entorno de Personas con Discapacidad que Precisan el Acompañamiento de Perros de Asistencia, para adaptar la realidad actual y amparar el derecho de las personas con discapacidad que necesitan de la ayuda de un perro de asistencia a acceder al entorno y, por ende, a una participación social 
efectiva. A su vez, es también importante reconocer el papel relevante de estos animales en la sociedad y la obligación que tienen tanto sus adiestradores como sus propietarios y usuarios de prestarles los cuidados necesarios para su bienestar y para que puedan adquirir la madurez física y emocional adecuadas para prestar un servicio indispensable a las personas con discapacidad.

El artículo 10.1.18 el Estatuto de Autonomía de la Región de Murcia considera competencia exclusiva de esta Comunidad Autónoma, entre otras referidas a la asistencia y bienestar social, la promoción e integración social de los discapacitados. Dentro de este amplio sector normativo preocupado por la consecución de ese objetivo de accesibilidad universal, se dicta la Ley 3/1994, de 26 de julio, por la que se regula el acceso a cualquier lugar de los disminuidos visuales graves acompañados de perro-guía.

Recientemente se ha publicado la Ley 4/2017, de 27 de junio, de accesibilidad universal de la Región de Murcia, cuyo artículo 28.5 dispone que en la normativa de desarrollo de la misma se regulará la tarjeta de estacionamiento de personas con discapacidad, especialmente las plazas de estacionamiento reservadas, beneficiarios, ámbito de aplicación y competencias de las administraciones públicas. El desarrollo reglamentario de la citada Ley, lo constituye el Decreto $4 / 2018$, de 24 de enero, por el que se regula la tarjeta de estacionamiento para personas con discapacidad en la Región de Murcia.

En Navarra, la Ley Foral 5/2010, de 6 de abril, de accesibilidad universal y diseño para todas las personas, "tiene por objeto garantizar la igualdad de oportunidades a las personas con discapacidad en relación con la accesibilidad universal y diseño para todos respecto a los entornos, los procesos, bienes, productos y servicios, así como en relación con los objetos o instrumentos, herramientas y dispositivos, de tal forma que los mismos se hagan comprensibles, utilizables y practicables por todas las personas, en igualdad de condiciones de seguridad, comodidad y de la forma más autónoma y natural posible" 22

En el ámbito autonómico vasco, la Ley 20/1997, de 4 de diciembre, sobre Promoción de la Accesibilidad, fue aprobada con la finalidad de garantizar la accesibilidad del entorno urbano, los espacios públicos, los edificios, los medios de transporte y los sistemas de información y comunicación, permitiendo su uso y disfrute de forma autónoma por todas las personas y en particular por aquellas con movilidad reducida, dificultades de comunicación, o cualquier otra limitación psíquica o sensorial de carácter temporal o permanente. A fin de cumplimentar lo dispuesto en esta ley, fue aprobado el Decreto 68/2000, 11 de abril, por el que se regulan las normas técnicas sobre condiciones de accesibilidad de los entornos urbanos, espacios públicos, edificaciones y sistemas de información y comunicación. Asimismo mediante el Decreto 256/2000, de 5 de diciembre, se regula la tarjeta de estacionamiento para personas con discapacidad Complementa la legislación en esta materia la Ley 10/2007, de 29 de junio, sobre Perros de Asistencia para la Atención a Personas con Discapacidad.

El Estatuto de Autonomía de La Rioja, aprobado por Ley Orgánica 3/1982, de 9 de junio, conforme a su actual redacción, el artículo 7.2 impone a los poderes públicos de la Comunidad Autónoma, la obligación de promover las condiciones para que la igualdad entre las personas sea real y efectiva. En base a este mandato se aprueban diferentes normas que tienen como objeto facilitar la integración de las personas con discapacidad en todos los niveles sociales. Al respecto, destacar la Ley 1/2000, de 31 de mayo, de perros guía acompañantes de personas con deficiencia visual, que tiene por objeto "reconocer y garantizar en la Comunidad Autónoma de La Rioja que toda persona que como consecuencia de su deficiencia visual vaya acompañada de perro guía

\footnotetext{
${ }^{22}$ Artículo 1 Ley Foral 5/2010, de 6 de abril, de accesibilidad universal y diseño para todas las personas.
} 
tiene derecho a acceder, junto con él, a cualquier lugar, establecimiento o transporte de uso público, con independencia de su titularidad pública o privada". ${ }^{23}$

Por su parte, la Ley 27/2007, de 23 de octubre, por la que se reconocen las lenguas de signos españolas y se regulan los medios de apoyo a la comunicación oral de las personas sordas, con discapacidad auditiva y sordo ciegas, hace referencia en sus artículos 13 y 22 a la accesibilidad y la participación política de dichas personas. Fruto de los mandatos estipulados en ella se aprueba la Orden 10/2011, de 28 de marzo, de la Consejería de Administraciones Públicas y Política Local, por la que se desarrolla el procedimiento de voto accesible que facilita a las personas con discapacidad visual el ejercicio del derecho de sufragio en las elecciones al Parlamento de La Rioja de 22 de mayo de 2011.

Por último, según el artículo 21 del Estatuto de Autonomía de Ceuta y Melilla, ambas ciudades ejercen competencias en materia de Ordenación del territorio, urbanismo y vivienda, y por tanto, pueden desarrollar normativas en materia de accesibilidad. En base a ello, los gobiernos locales de los municipios elaboran una serie de instrumentos para la promoción de la accesibilidad que reflejan la influencia de las Leyes Autonómicas sobre esta materia. Entre ellos se encuentran los Planes Municipales de Accesibilidad, concebidos como planes de actuación para suprimir las barreras en el municipio y las Ordenanzas Municipales integrales de accesibilidad, que suponen una transposición directa de los criterios establecidos en la legislación autonómica y disponen de un nivel ejecutivo y de aplicación mayor que las normas de rango superior. A través de estos instrumentos se establecen los criterios técnicos para desarrollar medidas de gestión y organización urbanística en materia de accesibilidad en el municipio.

Respeto a la aplicación práctica de la accesibilidad universal, actualmente podemos observar como existen diversos esfuerzos de recopilación legislativa de las normas reguladoras de la discapacidad en los ámbitos internacional, comunitario, nacional y autonómico, generados gracias al movimiento asociativo de la discapacidad, como el CERMI o la Fundación ONCE; y a las instituciones formales, como el Defensor del Pueblo o el Consejo General del Poder Judicial, que suponen un avance muy importante en esta materia.

En cuanto a los repertorios jurisprudenciales y de doctrina judicial, destacar que el Tribunal Constitucional ha establecido ${ }^{24}$ que el artículo 149.1.1 sólo presta cobertura a aquellas condiciones que guarden una estrecha relación, directa e inmediata con los derechos que la Constitución reconoce, con lo que parece excluir los pronunciamientos del artículo 49, fundamento de protección de las personas con discapacidad. No obstante la Ley 51/2003, de 2 de diciembre, de igualdad de oportunidades, no discriminación y accesibilidad universal de las personas con discapacidad (LIONDAU), no sólo se refiere a este artículo, sino también al 9.2, 10 y 14 del mismo Texto Constitucional, configurando su objeto en el establecimiento de medidas para garantizar y hacer efectivo el derecho a la igualdad de oportunidades de las personas con discapacidad. ${ }^{25}$

En el ámbito de las Comunidades Autónomas existe una gran cantidad de normas que regulan los derechos de las personas con discapacidad. A pesar de ello la jurisprudencia relacionada con su protección es escasa y en algunos ámbitos casi nula.

En materia de accesibilidad universal, destacar la Sentencia Civil 542/2018, Audiencia Provincial de Madrid, Sección 9, Recurso 654/2018 de 14 de Diciembre de 2018, que se pronuncia a favor de la realización de obras requeridas a instancia de los propietarios en cuya

\footnotetext{
${ }^{23}$ Artículo 1 Ley 1/2000, de 31 de mayo, de perros guía acompañantes de personas con deficiencia visual.

${ }^{24}$ STC 239/2002, de 11 de diciembre.

${ }^{25}$ Véase TORRES LÓPEZ, M.A. (2011) “La Discapacidad en el Derecho Administrativo”, Navarra:

Ed Aranzadi, Cizur Menor.
} 
vivienda local vivan, trabajen o presten servicios voluntarios, personas con discapacidad, o mayores de 70 años, con el objetivo de asegurar un uso adecuado a sus necesidades de los elementos comunes, así como la instalación de rampas, ascensores u otros dispositivos, en aplicación de lo dispuesto en el art. 17.2 de la Ley de Propiedad Horizontal. En el mismo sentido se pronuncia la Sentencia Civil 340/2019, Audiencia Provincial de Madrid, Sección 20, Recurso 272/2019 de 15 de Julio de 2019, invocando el mismo artículo 10.1.B, de la Ley de Propiedad Horizontal, que establece la obligación de la Comunidad de Propietarios de llevar a cabo las obras necesarias para la accesibilidad universal, y especialmente de las personas con discapacidad.

Las normas expuestas, se complementan con la existencia de innumerables políticas basadas en la plena igualdad de oportunidades, la no discriminación, la accesibilidad universal y el ejercicio real de derechos por parte de las personas con discapacidad en igualdad de condiciones respecto con el resto de ciudadanos. Para la consecución de estos objetivos, el Ministerio de Sanidad, Servicios Sociales e Igualdad y el Real Patronato sobre Discapacidad, han impulsado, con la participación del tejido asociativo de la discapacidad y con el resto de ministerios. Al respecto, el 12 de septiembre de 2014 se aprobó en Consejo de Ministros el Plan de Acción de la Estrategia Española de Discapacidad 2014-2020 que nace con el objetivo de contribuir a mejorar la situación de las personas con discapacidad en España, para ello se trata de concienciar a la ciudadanía de que este colectivo ha de tener garantizados sus derechos en igualdad de condiciones, estableciendo la importancia de la implementación de políticas que satisfagan los derechos sociales de forma efectiva, como las del conjunto de los ciudadanos. ${ }^{26}$

\section{Evolución de la regulación sobre accesibilidad en Portugal, en referencia a las personas con discapacidad.}

Respecto de Portugal, será a partir de la revolución democrática de 1974, origen de la actual Constitución Portuguesa de 1976, cuando comienzan a aprobarse leyes y planes de acción que exigen a las entidades públicas y privadas que garanticen la accesibilidad de los espacios públicos, los edificios e instalaciones colectivos y públicos, y la información y las comunicaciones, incluidas las nuevas tecnologías de la información.

En relación al mandato constitucional, regulado en el artículo 71 que obliga al Estado a establecer políticas de prevención, tratamiento, rehabilitación e integración respecto de las personas con discapacidad, se crea la Ley 38/2004, de 18 de agosto , que define las bases generales del régimen legal para la prevención, habilitación, rehabilitación y participación de personas con discapacidad, y establece que el Estado puede asignar a entidades públicas y privadas la promoción y el desarrollo de la política nacional de prevención, habilitación, rehabilitación y participación, asignándole un papel fundamental en esta labor a las organizaciones que representan a las personas con discapacidad. ${ }^{27}$

En desarrollo de esta norma se crea el Decreto Ley 163/2006 de 8 de agosto, que reemplaza el Decreto Ley 123/97, de 22 de mayo, define las condiciones de accesibilidad a cumplir en el diseño y construcción de espacios públicos, instalaciones públicas y edificios públicos y de viviendas.

\footnotetext{
26 MINISTERIO DE DERECHOS SOCIALES. Información sobre Discapacidad [En línea]: https://www.mscbs.gob.es/ssi/discapacidad/informacion/home.htm

${ }^{27}$ ASSEMBLEIA DA REPÚBLICA. "Cidadãos Portadores de Deficiência: Direito Nacional”. [En línea]: https:www.parlamento.pt/ArquivoDocumentacao/Documents/Deficiencia_Leg_Nacional.pdf
} 
La Resolución del Consejo de Ministros 9/2007, de 17 de enero, se promulgó con el fin de regular este Decreto. En ella se aprobó el Plan Nacional para la Promoción de la Accesibilidad, instrumento destinado a estructurar las medidas destinadas a mejorar la calidad de vida de todos los ciudadanos y, en particular, la realización de los derechos de ciudadanía para las personas con necesidades especiales. Posteriormente el artículo 3 del Decreto-Ley 136/2014, de 9 de septiembre, introduce nuevas modificaciones en este sentido, en relación con la Convención sobre los derechos de las personas con discapacidad, aprobada por la Resolución de la Asamblea de la República 56/2009.

El régimen de accesibilidad para edificios y establecimientos de uso público y edificios de viviendas se establece en el Decreto Ley 163/2006, de 8 de agosto con las modificaciones introducidas en el mencionado Decreto Ley de 2014.

En relación con el transporte, el Decreto-Ley 74/2007, de 27 de marzo regula el derecho de acceso para personas con discapacidad acompañados de perros de asistencia a lugares públicos, transporte y establecimientos y el Decreto Ley 307/2003, de 10 de diciembre, enmendado por Decreto Ley 17/2011, de 27 de enero, aprueba la tarjeta comunitaria de aparcamiento para personas con discapacidad que tienen movilidad restringida, la cual permite al titular de la tarjeta, beneficiarse de las facilidades comunitarias autorizadas en toda la Comunidad.

En materia de transporte aéreo, y en aplicación el Reglamento 1107/2006 del Parlamento Europeo y del Consejo de 5 de Julio de 2006, se promulga el Decreto Ley 35/2015, de 6 de marzo, que establece el régimen jurídico aplicable al contrato de transporte de pasajeros y equipaje, volúmenes portátiles, mascotas, bicicletas y otros bienes. En lo que respecta a los derechos de las personas con discapacidad y las personas con movilidad reducida cuando viajan en avión, establece normas para la protección y la prestación de asistencia, ya sea para protegerlos contra la discriminación o para garantizar que reciban asistencia.

El Decreto-Ley 58/2016, de 29 de agosto, extendió la obligación de brindar atención prioritaria a las personas con discapacidad, ancianos, mujeres embarazadas y personas acompañadas por niños a todas las entidades públicas y privadas que prestan servicios presenciales

La mejora de la relación de los ciudadanos con la Administración Pública, se establece en el Decreto-Ley 83/2018 de 19 de octubre, que establece la adopción de medidas adecuadas para garantizar a las personas con discapacidad el acceso, en condiciones de igualdad con los demás ciudadanos, a las tecnologías y los sistemas de información y comunicación, a desarrollar, promulgar y supervisar la aplicación de normas y directrices mínimas para la accesibilidad de las instalaciones y de los servicios abiertos al público o de uso público, así como a promover el acceso de las personas con discapacidad a nuevas tecnologías y sistemas de información y comunicación, incluida Internet. ${ }^{28}$

Respecto a la aplicación práctica de la legislación, esta tiene implicaciones transversales en todos los ámbitos de las políticas públicas, y es fundamental definir objetivos prioritarios que orienten la acción, teniendo como primer elemento fundamental el reconocimiento de que estamos ante ciudadanos con características y realidades muy diferentes, con grados diferenciados de autonomía / funcionalidad, que requieren de diferentes apoyos, teniendo en cuenta que los desafíos que enfrentan su inclusión son de muy diversa índole. En base a la necesidad de profundizar en el trabajo ya realizado, a través de la Estrategia Nacional de Discapacidad 2011-2013 (ENDEF), el XXII Gobierno Constitucional de Portugal, trata de

\footnotetext{
${ }^{28}$ ASOCIACIÓN PORTUGUESA DE DEFICIENTES. Legislação. [En línea]: https://www.apd.org.pt/index.php/noticias.
} 
implementar una Estrategia Nacional de Inclusión de Personas con Discapacidad, para el período 2021-2025 (ENIPD 2021-2025. ${ }^{29}$

En lo que respecta a los Tribunales portugueses, existe una vasta jurisprudencia sobre la aplicación del principio de igualdad y sobre normas relativas a situaciones de discapacidad [cf., en particular, Sentencias No. 46/86 (Sentencias del Tribunal Constitucional, $7^{\circ}$ vol.) No. 330/93 (Sentencias de la Corte Constitucional, $25^{\circ}$ vol.) No. 563/96 (Sentencias del Tribunal Constitucional, $33^{\circ}$ vol.) 319/00 (Sentencias del Tribunal Constitucional, $47^{\circ}$ vol.) Sentencia No. 377/02 y 378/00 (Sentencias del Tribunal Constitucional, $47^{\circ}$ vol.), aunque en materia de accesibilidad los Tribunales portugueses tienen escasos o nulos pronunciamientos.

\section{Discusión de resultados.}

El modelo de accesibilidad en relación con las personas con discapacidad, no es independiente de la concepción que tradicionalmente ha tenido la sociedad de esta situación. La evolución social, política y normativa de estos dos países ha sido determinante en la adopción de nuevas formas de entender la accesibilidad. Actualmente, ambos países están inmersos en el nuevo paradigma de la accesibilidad universal superando conceptos anticuados como el de eliminación de barreras, adaptación, acondicionamiento,..., la accesibilidad se entiende como derecho, más exactamente, como presupuesto necesario para el ejercicio pleno de derechos, que tiene como correlato lógico la consideración de la falta de accesibilidad de los entornos, productos y servicios a disposición del público como una discriminación contra las personas con discapacidad. Este cambio de paradigma viene consagrado por la Convención Internacional sobre los Derechos de las Personas con Discapacidad de la ONU, adoptada en diciembre de 2006, firmada y ratificada por ambos países. ${ }^{30}$

Tras el análisis de la normativa más importante en materia de accesibilidad en relación con las personas con discapacidad, se puede afirmar que ambos países se ha producido una importante regulación normativa en este sentido, aunque en España tradicionalmente hemos ido un "pasito" por detrás, debido a las circunstancias sociopolíticas vividas. En este sentido resaltar que aunque el artículo constitucional español que regula la discapacidad, tiene una notable influencia de la Constitución portuguesa, y a pesar de ser esta su precursora, su redacción es más obsoleta al estar inspirada principalmente en el modelo médico e incluyendo términos más peyorativos que su homónima portuguesa.

En relación con la normativa de desarrollo (leyes y reglamentos), se puede afirmar que existe mayor dispersión normativa en España, que en Portugal. Esto es debido principalmente a que al ser España un estado descentralizado se han transferido muchas competencias a las comunidades autónomas, en numerosas materias, esto provoca que exista sobreabundancia de normas. A pesar de que el Estado regula el marco normativo básico sobre accesibilidad, son las Comunidades Autónomas las que por muchos años se erigen en las únicas instancias para poder afrontar las cuestiones de accesibilidad desde un enfoque normativo. Esto da pie a la promulgación de 17 leyes autonómicas, 19 si contamos con las ordenanzas de las ciudades de Ceuta y Melilla. Las notas que caracterizan esta legislación son la diversidad de criterios (incluso de índole técnica), concepción anticuada centrada en la accesibilidad del medio físico y escasa eficacia práctica de las disposiciones legales.

\footnotetext{
${ }^{29}$ INSTITUTO NACIONAL PARA A REABILITAÇÃO: Planeamento, Coordenação e Execução das Políticas Nacionais destinadas à promoção dos direitos das Pessoas com deficiencia. Noticias [En línea]: https://www.inr.pt/noticias/-/journal_content/56/11309/433133.

30 Véase FRAGOEIRO, M. (1994),"Programas comunitários e sua aplicação à população deficiente", in AIRES GAMEIRO (Dir) e outros, Reabilitação Recíproca, Lisboa, Hospitalidade.
} 
Paralelamente a la regulación autónoma existe la regulación municipal de las Corporaciones Locales, fundamentalmente, los Ayuntamientos que tienen ciertas competencias en la regulación de las condiciones de accesibilidad aplicables en su término municipal. A través de las denominadas ordenanzas municipales, los Ayuntamientos pueden concretar o a veces ampliar la normativa emanada del Estado o de las Comunidades Autónomas, por lo que son considerados como poder público productor de Derecho, aunque sea residualmente, en materias de accesibilidad. Además, disponen de atribuciones en cuestiones de política y policía urbanísticas, lo que les confiere la posibilidad, escasamente ejercida, hay que decir, de fiscalizar, supervisar y sancionar, en su caso, aquellas actuaciones contrarias a la eliminación de barreras. En general, el juicio sobre el modo de actuar las Corporaciones Locales en cuestiones de accesibilidad es negativo, ya que no han ejercido estas competencias con convicción y determinación, sino de una forma errática y sin vigor, lo que ha contribuido a conformar una situación anárquica y poco respetuosa respecto a los derechos de las personas con discapacidad.

En Portugal, al ser un Estado centralizado, la principal normativa en materia de accesibilidad, emana de la administración central. A través del establecimiento de un Plan Nacional para la Promoción de la Accesibilidad, regulado por Resolución del Consejo de Ministros, se establece que las obligaciones de las autoridades locales son bastantes similares a las de la administración central, que solo puede intervenir en el marco de sus facultades de supervisión. En base al modelo constitucional que consagra el principio de autonomía local, y el Decreto Ley 163/2006 confiere a los municipios la obligatoriedad de incorporar la accesibilidad en los Planes Directores Municipales en los que se planifica el urbanismo y dispone que los consejos municipales y la Inspección General de los Gobiernos Locales elaboraran informes anuales sobre la situación existente en el marco de sus facultades de inspección, junto con otras cuestiones materiales relacionadas con la accesibilidad. ${ }^{31}$

En consecuencia la normativa portuguesa que regula la accesibilidad en relación con las personas con deficiencias es menos extensa que la española, está organizada de modo más concreto y al no existir las comunidades autónomas, solo confiere poderes al Estado central y a los municipios, evitando duplicidades y conflictos de normas, lo que agiliza la aplicación y la uniformidad normativa, evitando su dispersión. En este sentido agregar que aunque Portugal "comenzó a florecer" un "buen ejemplo europeo", han tardado en aparecer sobre el terreno los resultados de los programas públicos y privados sucesivas para mejorar la movilidad de personas con deficiencia" 32 .

En cuanto a la aplicación de las políticas públicas para la mejora de la accesibilidad universal, se ha recorrido un largo camino en ambos países, que tomó impulso a raíz del año 2003 proclamado como "Año Europeo de la persona con discapacidad", el cual originó la creación Planes y Programas en relación con la accesibilidad de las personas con problemas de movilidad.

En Portugal encontramos un conjunto de organismos públicos y asociativos similar a España, si bien en el país luso no existen estructuras administrativas regionales consolidadas. Existe un organismo homólogo al IMSERSO español que es el Instituto Nacional o Aproveitamento dos Tempos Livres dos Trabalhadores (INATEL). Dependiente también del Ministerio de Solidaridade e Salud, se halla el Instituto Nacional para a Reabilitação (INR). Igualmente, posee un amplio y complejo entramado de asociaciones y ONGs, con sus correspondientes webs, volcadas en temas de accesibilidad, discapacidad y turismo accesible. ${ }^{33}$

\footnotetext{
${ }^{31}$ Véase TELES, P. (2012) “Accesibilidad y Movilidad para Todos” Portugal. Instituto de Discapacidad

32 GONÇALVES, C. (2003), "Enquadramento familiar das pessoas com deficiência; uma análise exploratória", Revista de Estudos Demográficos no 33, Lisboa.INE.

${ }^{33}$ GABINETE DA SECRETÁRIA DE ESTADO ADJUNTA E DA REABILITAÇÃO E SECRETARIADO NACIONAL PARA A REABILITAÇÃO E INTEGRAÇÃO DAS PESSOAS COM DEFICIÊNCIA (2006), $1^{\circ}$
} 
En España el Real Patronato sobre Discapacidad ha presentado los resultados del 'Estudio de accesibilidad de los bienes y servicios a disposición del público en España, 2017', elaborado por Fundación ONCE, en el que se destacan las buenas puntuaciones del sector turismo, el avance en movilidad de los transportes y cierta insatisfacción de los usuarios con discapacidad hacia la accesibilidad del sector financiero y de seguros. ${ }^{34}$

Lo que vemos en la vida cotidiana en Portugal es que los edificios públicos son realmente adecuados para personas con necesidades especiales y movilidad reducida. Sin embargo, los edificios privados (especialmente los más antiguos) dejan mucho que desear. Muchos edificios tienen escaleras para subir al edificio y no hay rampas de acceso. Muchas aceras no están preparadas para que los usuarios de sillas de ruedas crucen la calle y la movilidad sigue siendo complicada. Los grandes centros urbanos de Portugal, Lisboa y Oporto tienen más estructura, pero las ciudades más pequeñas aún no están completamente preparadas para recibir personas con movilidad reducida. Los autobuses tienen rampas de escalada principalmente y el transporte público, como los trenes y el metro, está preparado para personas discapacitadas. ${ }^{35}$

El pasado 31 de julio de 2019 el Gobierno portugués presentó la Guía práctica "Los derechos de las personas con discapacidad en Portugal", libro electrónico que, recopila información sobre diversas áreas de interés y respeta los servicios públicos en Portugal, con el objetivo de promover la autonomía y los ciudadanos con discapacidad, facilitar la toma de decisiones y la promoción de la inclusión. Esta guía proporciona información sobre apoyo social, medidas de empleo y apoyo vocacional, beneficios sociales y fiscales e información práctica sobre la red de Contadores de inclusión o cómo solicitar un Certificado médico de discapacidad multipropósito. Además es una herramienta formativa, ya que aclara la terminología correcta a adoptar, ayudando a las personas con discapacidad a hacer realidad sus derechos y a señalar las prácticas de discriminación por discapacidad.

En España existe un documento similar, que se ha publicado en ocho reediciones y numerosas reimpresiones efectuadas desde que en 1987 cuando se publicó por primera vez el "Curso básico sobre evitación y supresión de barreras arquitectónicas urbanísticas y del transporte”, y que hoy ha pasado a titularse "Manual para un entorno accesible". Este documento editado por Real Patronato sobre Discapacidad, organismo perteneciente al Ministerio de Trabajo y Asuntos Sociales, tiene una doble vertiente técnica y didáctica, e incorpora actualizaciones de aspectos técnicos y normativos que han ido apareciendo en estos últimos años.

\section{Conclusiones.}

España y Portugal están aplicando un nuevo paradigma sobre la accesibilidad universal que conlleva la promulgación de nueva normativa relacionada y una forma innovadora de organización de las políticas públicas. El conjunto de estas acciones se orienta a asegurar el derecho al acceso a todos los espacios, tanto públicos como privados, en sectores que afectan a la vida diaria de las personas con discapacidad.

Esto es debido al cambio en las concepciones, que afecta a los derechos de las personas con discapacidad, influyendo no solo en la terminología usada, sino también a nivel legislativo, a las

\footnotetext{
Plano de acção para a integração das pessoas com deficiências e incapacidades, Lisboa: IEFP. [En línea]: http://www.inr.pt.

${ }^{34}$ REAL PATRONATO SOBRE DISCAPACIDAD. Centro Español de Documentación sobre Discapacidad. [En línea]: https://www.cedd.net/es/actualidad/noticias/publicado-un-estudio-sobre-la-accesibilidad-de-los-bienes-yservicios-a-disposicin-del-pblico-en-espaa/0-394/
} 
prácticas implementadas, a las actitudes de las administraciones, y finalmente a la propia sociedad.

Las instituciones administrativas y jurídicas combaten los focos de exclusión e impulsan el desarrollo de la planificación inclusiva, con la creación de entornos inteligentes y accesibles, que se encuentran en estrecha colaboración entre la ciudad y las organizaciones representativas de las personas con discapacidad, y se constituyen en un espacio para la convivencia y la realización personal de este colectivo. La inclusión se opone a la segregación y al aislamiento, al igual que la variedad. La dificultad se configura como oportunidad para el enriquecimiento.

En ambos países, la tendencia imperante es facilitar la accesibilidad a todas las personas, especialmente las que sufren algún tipo de discriminación, como son las personas con discapacidad. Actualmente, gracias a las mejoras introducidas en esta materia, se puede caminar en una sociedad con menos obstáculos, acceder a edificios públicos y museos, las personas con dificultad de vista pueden escuchar las webs... Esperemos que en ambos países se siga la tendencia iniciada, trabajando en entornos más accesibles para todos.

\section{Bibliografía.}

- ALONSO LÓPEZ, F. (2007) "Los ejes determinantes de las políticas de igualdad de oportunidades. La accesibilidad universal y el diseño para todos", en LORENZO, R. de y LÓPEZ BUENO, L. C. Tratado sobre discapacidad, Madrid: Aranzadi.

- $\quad$ ALLPORT, G. W. (1962), “La naturaleza del prejuicio”, Buenos Aires: Eudeba.

- ASÍS, R. (2007) "Derechos humanos y discapacidad. Algunas reflexiones derivadas del análisis de la discapacidad desde la teoría de los derechos", en CAMPOY CERVERA, I. y PALACIOS, A. Igualdad, no discriminación y discapacidad, Madrid: Dykinson,

- CAMPO Y CERVERA, I. y PALACIOS, A. (2007) "Igualdad, no discriminación y discapacidad", Madrid: Dykinson.

- CARMONA CUENCA, E. (1992) "Las normas constitucionales de contenido social: delimitación y problemática de su eficacia jurídica", Revista de Estudios Políticos, n. ${ }^{\circ}$ 76, págs. 19-34.

- FRAGOEIRO, M. (1994),"Programas comunitários e sua aplicação à população deficiente", in AIRES GAMEIRO (Dir) e outros, Reabilitação Recíproca, Lisboa: Hospitalidade.

- GARCÍA MARTÍNEZ, A. Y SIEIRA, S. (2003) “Sinopsis del Artículo 49”, Congreso de los Diputados, Madrid. [En línea]:

https://app.congreso.es/consti/constitucion/indice/sinopsis/sinopsis.jsp?art=49\&tipo=2 \#: :text=49\%20son $\% 2 \mathrm{C} \% 20 \mathrm{seg} \% \mathrm{C} 3 \% \mathrm{BAn} \% 20 \mathrm{el} \% 20$ tenor, habituales $\% 20 \mathrm{de} \% 201 \mathrm{a} \%$ 20vida\%20social.

- GONÇALVES, C. (2003), "Enquadramento familiar das pessoas com deficiência; uma análise exploratória", Revista de Estudos Demográficos n 33, Lisboa: INE. 
- PALACIOS, A. (2008) "El modelo social de discapacidad: orígenes, caracterización y plasmación en la Convención Internacional sobre los Derechos de las personas con discapacidad”. Madrid: Ediciones Cinca.

- TELES, P. (2012) “Accesibilidad y Movilidad para Todos" Portugal: Instituto de Discapacidad

- TEROL BECERRA, M. J. (2010). "III Foro andaluz de los derechos sociales. Diversidad y ciudadanía”, Valencia: Tirant lo Blanch.

- TORRES DEL MORAL, A. (2010) "La incorporación de los derechos de los discapacitados por el constitucionalismo de la segunda posguerra", en TEROL BECERRA, M. J. (director), III Foro andaluz de los derechos sociales. Diversidad y ciudadanía, Valencia: Tirant lo Blanch.

- TORRES LÓPEZ, M.A. (2011) "La Discapacidad en el Derecho Administrativo", Navarra: Ed Aranzadi, Cizur Menor.

\section{Webs de interés.}

- ASOCIACIÓN PORTUGUESA DE DEFICIENTES. Legislaçã . [En línea]: https://www.apd.org.pt/index.php/noticias. Consultado con fecha 10 de abril de 2020

- ASSEMBLEIA DA REPÚBLICA. "Cidadãos Portadores de Deficiência: Direito Nacional". [En línea]: https:www.parlamento.pt/ArquivoDocumentacao/Documents/Deficiencia_Leg_Nacio nal.pdf. Consultado con fecha 25 de abril de 2020.

- CERMI (Comité Español de Representantes de Personas con Discapacidad). [En línea]: http://www.cermi.es/cermi/. [Consultado con fecha 20 de agosto de 2020].

- CONSTITUCIÓN DE PORTUGAL, 1976. [En línea]: https://constituteproject.org/constitution/Portugal_2005.pdf?lang=es. [Consultado con fecha 15 de febrero de 2020].

- GABINETE DA SECRETÁRIA DE ESTADO ADJUNTA E DA REABILITAÇÃO E SECRETARIADO NACIONAL PARA A REABILITAÇÃO E INTEGRAÇÃO DAS PESSOAS COM DEFICIÊNCIA (2006), $1^{\circ}$ Plano de acção para a integração das pessoas com deficiências e incapacidades, Lisboa: IEFP. [En línea]: http://www.inr.pt. [Consultado con fecha 20 de marzo de 2020].

- INSTITUTO NACIONAL PARA A REABILITAÇÃO: Planeamento, Coordenação e Execução das Políticas Nacionais destinadas à promoção dos direitos das Pessoas com deficiencia. Noticias [En línea]:

https://www.inr.pt/noticias/-/journal_content/56/11309/433133. [Consultado con fecha 30 de mayo de 2020]. 
- NACIONES UNIDAS. Personas con Discapacidad. Departamento de Asuntos Económicos y Sociales. [En línea]: https://www.un.org/development/desa/disabilitieses/. [Consultado con fecha 15 de julio de 2020].

- NACIONES UNIDAS. Oficina del Alto Comisionado para los Derechos Humanos. [En línea]: https://www.ohchr.org/documents/publications/advocacytool_sp.pdf. [Consultado con fecha 28 de julio de 2020].

- REAL PATRONATO SOBRE DISCAPACIDAD. [En línea]: https://www.cedd.net/ [Consultado con fecha 1 de octubre de 2020].

- REAL PATRONATO SOBRE DISCAPACIDAD. Centro Español de Documentación sobre Discapacidad. [En línea]: https://www.cedd.net/es/actualidad/noticias/publicadoun-estudio-sobre-la-accesibilidad-de-los-bienes-y-servicios-a-disposicin-del-pblicoen-espaa/0-394/. [Consultado con fecha 1 de octubre de 2020].

- UNIVERSIDAD DE SALAMACA. Servicio de Información sobre Discapacidad. [En línea]: https://sid.usal.es/secciones/discapacidad.aspx. [Consultado con fecha 30 de abril de 2020] 